\title{
Identifying Initial Conceptions of Engineering and Teaching Engineering
}

\author{
William Thatcher* (D) and Helen Meyer \\ School of Education, College of Education, Criminal Justice, and Human Services, University of Cincinnati, \\ PO Box 210002, Cincinnati, OH 45221, USA; meyerhe@ucmail.uc.edu \\ * Correspondence: thatchwh@mail.uc.edu
}

Received: 31 October 2017; Accepted: 5 December 2017; Published: 7 December 2017

\begin{abstract}
The present study reports the use of an interview task to identify the initial conceptions of engineering and teaching engineering held by secondary mathematics and science teachers upon entering a professional development program. Results obtained from this task gave insight on several points, including: (1) the requirements for a task to be considered engineering; (2) the role of a student in practicing engineering; (3) the role of the teacher in teaching engineering; and (4) the differences in discourse choices, between mathematics and science teachers, pertaining to conceptions of engineering and teaching engineering. Through understanding the beliefs of our teachers, appropriate action may be taken to ensure that we are fostering desirable classroom environments, as well as better understand how to prepare them for challenges that may present themselves in the classroom.
\end{abstract}

Keywords: teaching engineering; conceptions; teacher beliefs; teacher change; professional development

\section{Introduction}

The origins of democratizing education in the United States may be traced back to the early 19th century to contributors such as Henry Barnard and Horace Mann, who believed that developing a common curriculum would be the best way to properly prepare our children to be active democratic citizens upon entering society. Barnard saw the most optimal curriculum as one which "...embraces the harmonious development of [the] whole nature of the child ... [and that] it shall end in a preparation for the real business of life-not for any particular pursuit, but for any and every pursuit [1] (p. 41)." As we fast-forward to contemporary American society, we have seen in recent years, another effort to try and create a common level of curriculum, with particular focus in the STEM fields to pass along 21st century skills. In attempts to revive the competitive spirit of American education within the modern global economy, and in hopes of better preparing our students for college, careers, and life, many states have taken to adopting the Common Core Standards for Mathematics (CCSM) and the Next Generation Science Standards (NGSS) into their curriculum [2,3].

These standards aim to make mathematics and science content more applicable and engaging, particular to those students who may not identify as strong STEM students in traditional style classrooms. Developers hope that through exposing a wider audience to applied science topics, more students may be drawn to pursue STEM careers further down the road [2,3]. Given the recent nature of adopting these standards, however, many teachers have been left wondering how to best implement these new classroom practices. One possible solution is the integrating of engineering-based activities into classrooms. Research on the matter has shown that engineering design can be used as a lens for authentic learning which can foster student understanding of STEM concepts [4-6]. Yet, the research detailing how to best integrate engineering into the classroom is still limited in the literature. 
As a result, if engineering concepts are to be adopted as part of the curricula, an effort needs to be made at the professional development level to properly equip our teachers with the tools needed to face challenges that lie ahead. By expanding mathematics and science teachers' understanding of engineering and teaching engineering, we can equip them with a knowledge bank that may be drawn upon later when planning and executing their respective curriculum.

The study reported here is a subset of a larger professional development program which was aimed at helping secondary mathematics and science teachers learn more about engineering, as well as how to best develop and carry out engineering-based units in their classrooms. Upon entry into the program, several teachers volunteered to participate in an interview task to understand their conceptions of teaching engineering. The research question addressed in this paper is: What are the initial conceptions of engineering and teaching engineering held by mathematics and science teachers? It is hoped that the results presented here may act as a reference for those wishing to conduct PD programs on integrating engineering into curricula. If we wish to best improve the quality of teaching a particular subject, we must first take the time to understand the thought processes of those who are teaching the subject [7], as these beliefs are rich with detail and generally not homogenous.

\section{Theoretical Framework}

\subsection{Engineering Education}

The use of engineering in science teaching may be traced back to Science for All Americans [8], and ideas of scientific literacy, with typical manifestations being activities for students such as the 'egg drop challenge', or catapult designs. In early conceptions, engineering activities were an opportunity for authentic learning in science and mathematics [4,5]. However, with the adoption of new mathematics and science standards by many states in the U.S., engineering is now formally established as a component of a rigorous education. NGSS placed engineering on an equivalent plane as scientific inquiry, creating a substantial shift in the frequency and quality of its role in instruction. Inherent to this shift was reaching some consensus of what constitutes engineering in $\mathrm{K}-12$ classrooms.

In general, there is agreement that engineering includes knowing and using the engineering design process (EDP). NGSS broadly defines the EDP in a similar way to prior definitions given in the literature [9-12]. Engineering in K-12 Education: Understanding the Status and Improving the Prospects [13] analyzed available engineering curricula, determining that their primary focus was the design process. This design process included: problem identification, research/gathering information, identifying constraints, generating a potential solution, model building and solution testing, as well as evaluating results (repeating these steps as necessary). This focus on the design process was not considered by the authors to be sufficient in enabling students to understand engineering. Instead, a full teaching of engineering, in addition to a focus on the design process, should include: rigorous uses of mathematics and science, increased exposure to engineering careers, and connections to individual and societal problems.

\subsection{Challenge-Based Learning}

Challenge-based learning (CBL) acted as the primary framework through which the program participants in this study were introduced to engineering instruction. CBL is an extension of problem-based learning, where now the students and teacher work together as collaborators to solve a given challenge at hand. Each lesson begins with an overarching concern or challenge, relating to a real societal issue, which is then broken down into smaller constituent questions. Solutions to these smaller questions then come together, in order to address the larger challenge [14]. In most instances, CBL environments have an engineering design process (EDP) embedded within it to strengthen essential 21st century skills $[9,12,15]$, bringing about a learning context, increased motivation for learning, creating and testing products, and defining a 'best solution'. CBL activities allow for students to explore different variables which impact the created products' effectiveness, and get exposed 
to, and familiar with, multiple solution outcomes. This is in contrast to traditional EDP activities, which normally cease once all design criteria have been satisfied [16-18].

\subsection{Teacher Beliefs}

It has been well established in the teacher cognition literature that the beliefs teachers hold about class content, as well as the learning potential of their students, has a significant influence over their decision making in the classroom [19-21]. Similar to the issues experienced with trying to change students' conceptions, teacher conceptions have also proven difficult to change. Yet, this has shown to be a necessary endeavor when trying to alter teaching practices in hopes of improving student learning [22,23]. Therefore, if we wish to truly improve the quality of teaching a particular subject, an effort must first be made to understand the beliefs held by those teaching the subject [7]. With this knowledge in hand, professional development programs may then be utilized to cultivate teacher beliefs that will foster desirable classroom environments.

\section{Materials and Methods}

\subsection{Research Context}

The current study was a subset of a two-year longitudinal professional development program aimed at helping secondary mathematics and science teachers learn more about engineering and how to integrate engineering units into their curricula. The program took place at a large Midwest university in the U.S. All teachers were recruited to the program through a partnership project between the university and a dozen local school districts. Upon joining, several teachers volunteered to participate in an interview task which was developed to explore conceptions of teaching engineering. Those who participated, partook in the interview task at the beginning of their first summer in the program.

\subsection{Interview Task}

Inspired by the Conceptions of Teaching Science (CTS) task presented by Hewson \& Hewson [7], an interview task was developed for this study that enabled the researchers to explore the conceptions of teaching engineering held by the respondents, and was coined as the Conceptions of Teaching Engineering (CTE). When discussing the 'conceptions of engineering', we are referring here to: the set of ideas, understandings, and interpretations of experience concerning the teacher and teaching, as it relates specifically to engineering and teaching engineering. It investigates the interviewees understanding of the relationships between engineering as content, process, and profession, as well as the teachers' views of the relationship between the teaching and learning of engineering.

The structure of the task utilizes an "interview about instances" technique, which was devised by Osborne \& Gilbert [24]. When carrying out this technique, each person interviewed is given a list of instances, and asked to explore each instance within the confines of a particular label [24,25]. In this case, the particular label in question was teaching engineering. The CTE interview consists of eleven scenarios which vary along the following constructs: (1) teacher/adult instructional presence; (2) process, content, and skill development; (3) explicitness of links to school Science or Mathematics content; (4) grade levels or age of students mentioned; (5) ease of identification of engineering in the activity. Out of the eleven scenarios, none explicitly used the term 'engineering' or referred to teaching engineering; however, four instances modeled typical engineering topics, products, or tasks. The scenarios may be seen below in Table 1 . 
Table 1. Conceptions of Teaching Engineering (CTE) Protocol.

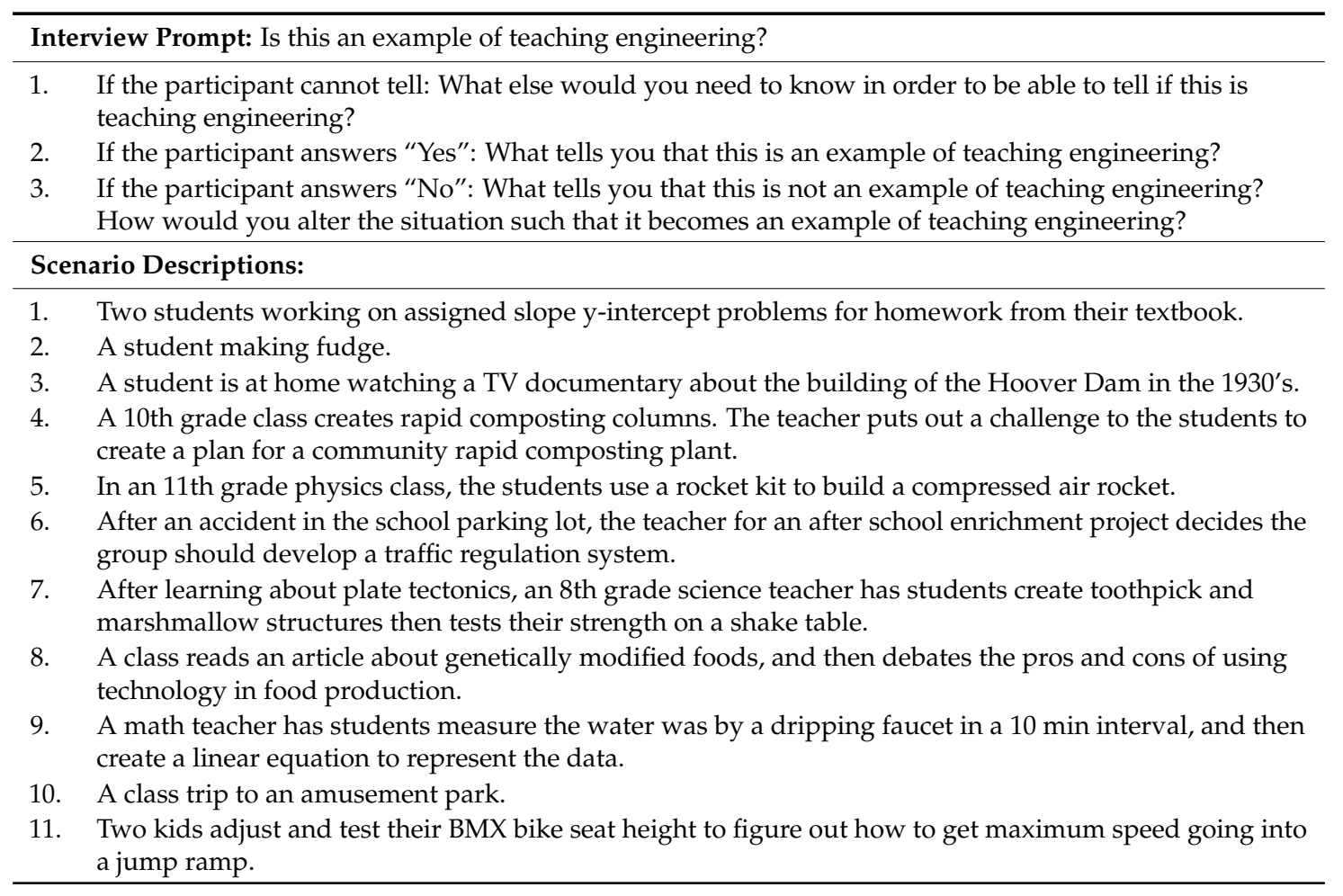

The participants were given a sheet listing all eleven scenarios as a reference upon request, and the interviewer read through each scenario sequentially. Upon reading a scenario, the interviewer then posed the question, "Is this an example of teaching engineering?" Generally, this resulted in a dichotomous response (i.e., yes, or no). From here, the respondent was probed to explain their reasoning. If they agreed to the prompt, they were asked to explain why they believed this to be so. Alternatively, if they did not agree, they were asked why they did not find the instance to be teaching engineering, as well as how they would alter the scenario such that it would become an example of teaching engineering. The ambiguity of the scenario descriptions allowed for a variety of organic responses, with no interference or influence from the interviewer. Interestingly, rather than address whether or not they found the scenario to be an example of teaching engineering, most participants chose to explore whether they believed the scenario to be an instance of students practicing engineering. This allowed for an analysis to determine what components, in the eyes of the participants, are deemed essential to practicing engineering.

\subsection{Participant Information}

From the larger professional development program population of 96, a total of: 16 teachers volunteered to participate in the CTE interview task. The collective was a well balanced mix of urban and suburban math $(n=7)$ and science $(n=9)$ teachers, from both middle school $(n=8)$ and high school $(n=8)$ settings. In terms of gender, 12 identified as being female, with the remaining 4 identified as male.

\subsection{Data Analysis}

The entire interview process was digitally recorded, and then sent out to be transcribed externally. These transcripts then underwent qualitative thematic analysis by each of the researchers. Standard codes and definitions for the CTE interviews were derived from the literature on engineering education, with particular attention to aspects detailed in Engineering in K-12 Education, which elaborated learning and instructional aspects beyond simply the EDP. Further contributors to 
the initial code set were transcripts taken from faculty professional development activities which had been introducing the CBL and the EDP, along with several partial CTE interviews conducted with engineering faculty members who collaborated on this project. The research team then independently coded one PD participant's CTE interview to check for standardization and emerging codes. A code set was then developed and agreed upon by the research team. These codes included elements of the design process and the specific non-design elements of careers, societal challenges, modeling, constraints and parameters, pros and cons (trade-offs), content, and optimization.

Once all of the gathered CTE-1 responses had been read through, transcript excerpts identifying specific constituents to practicing engineering were consolidated into a single summary table. From here, ideas that appeared across codes were identified, and new codes began to emerge within the design cycle category. The data was then reanalyzed, with the specific intent of pinpointing the emergent codes. This final code set may be seen below in Table 2, and will henceforth be referred to as 'components' of engineering. Finally, a third analysis sought to distinguish when the teachers specifically defined engineering activities through the lens of either a student or a teacher as the primary agent in their response.

Table 2. Final Code Set: 'Components' of Engineering.

1. Application/Real-World Context: direct application of classroom knowledge to a real-world problem or concern.

"I feel like it's just like basic, traditional work and it doesn't have any application to it."-Briana (95-96)

2. Creating a Product/Design/Model: hands-on activity involving the creation of a product/design/model.

"I think that's engineering because, they're designing, they already designed or created the product and now they're looking for larger global and social applications..."-Samuel (414-416)

3. Experimentation: conducting experiments (planned, as well as trial and error); troubleshooting errors in design process; gathering empirical data.

"Now that can be definitely teaching engineering because they're doing some tests... have a goal in mind, and then they just keep refining the process and taking information and readjusting."-Houston (220-222)

4. Background Research: developing a knowledge base to better address the task at hand.

"I don't think that that's engineering process. That's more background knowledge and just gathering information. It's definitely part of the process, it's just not the full, I don't think you get the full experience, the full process."-Holly (267-268; 273-274)

5. Revision Process: Refining or revising the design such that the process or product is improved.

"Are these solutions the most economic way to do this? Is this the best way and then redefining... designing, redesigning and... rethinking what happens."-Abby (271-274)

6. Challenge/Multistep-Problem: open-ended problem with multiple solutions.

“... it would need to have some kind of challenge or problem solving piece that would be solving a real world problem."-Claire (277-279)

7. Brainstorming: developing a set of possible solutions and upon weighing constraints, determining the 'best'.

“... evaluate, brainstorming and picking the best solutions and finding alternatives and then trying it."-Mason (339-341)

8. Communication: challenges are faced in a group setting rather than an isolated one; results are relayed to external parties outside of the classroom.

\footnotetext{
"Because they have to go through their own process and refine it and come up with pros and cons of their own plan and, since it's going to effect the community, they'll have to relay information to key people and cooperate with each other, the community too."-Olivia (211-215)
} 


\section{Results}

The results presented below are given through the view of the teachers' conceptions, and explore the following questions: (1) What is required for a task to be considered 'engineering'? (2) What is required of students for a task to be considered 'practicing engineering'? and (3) What is the role of the teacher in teaching engineering? Following these sections, there will be a discussion on the response differences observed between math and science teachers. When presenting each component, a fraction will be given in parentheses that follow. This corresponds to the number of participants, relative to the whole, who mentioned the component in at least one of their scenario responses.

\subsection{Requirements for a Scenario to Be Considered Engineering}

The most frequently mentioned component of engineering (present in $\sim 36 \%$ of total responses) was that there must be some Application/Real-World Context (16/16). Both sets of teachers were quite vocal that establishing a connection to real-world concerns is the primary ingredient in practicing engineering. Inherent to having a sound application, the task at hand must also be a Challenge/Multistep Problem (12/16). That is to say, in order for the task to be considered engineering it cannot be a single question that upon addressing, resolves the entire concern. There must be a breaking up of a larger complex problem into multiple smaller problems whose combined solutions then position the student such that they may address the overarching concern. Furthermore, the task must involve Creating $a$ Product/Design/Model (15/16). There was a clear understanding from these teachers that commonly, engineering work is not something that is done on a purely theoretical level. Rather, it is used to create something which may be of use on a larger scale than the classroom. As a result, not only must the task given to students have an application, and consist of multiple smaller steps to address an overarching concern, but it must also end with creating a final product/design/model.

\subsection{The Role of the Student in Practicing Engineering}

From the students' perspective, carrying out an engineering task is not a simple feat, but involves a precise weaving together of several different elements. The first step is to conduct Background Research $(15 / 16)$. Before any kind of hands-on activity can occur, there must be ample time given to developing a knowledge base which will then be utilized in the activity. This will allow students to gain a better understanding of not only what they are doing, but also (and perhaps more importantly) why they are doing what they are. Following time for background research, there must be a period of Brainstorming (10/16). This is the time in which multiple solutions to approaching the problem at hand will be generated. Intrinsic to this brainstorming multiple solutions is weighing of parameters and consideration of constraints which then allow for a 'best' solution to be determined.

Upon developing a best solution, comes the actual Experimentation (15/16) portion. This is the time for conducting various tests and gathering empirical data. Often times these tests will not be a smooth or polished process, and so troubleshooting of problems that occurred should be carried out to understand why one gathered the results they did, and what they can do differently to improve the process or their results. This leads to a Revision Process (15/16). During this time, the experimental design or process of carrying out an experiment is refined and adjusted so as to reach some optimal end. Once some predetermined optimal end has been reached, the students must engage in Communication $(9 / 16)$. This is not only communication amongst one another, or with the teacher, but also to some entity which exists outside of the classroom. Again, the task should be an application which has an effect on a scale larger than simply the classroom, and so the communicating of these results to an outside party will allow for the students to gain the experience of compacting their work and struggles into a format that will be appropriate for laymen. 


\subsection{The Role of the Teacher in Teaching Engineering}

The primary way in which the role of the teacher came about in responses was in the setting of goals for students to reach. Tasks involving engineering were conceived to have multiple possible solutions, and thus it was the job of the teacher to set constraints or boundaries which scaffold the students' experiences into reaching some 'optimal' end. The majority of respondents believed that an instructor must be present, in order for the students to truly be learning and practicing engineering. However, when it came to scenarios 3 and 11, there were some who saw that with careful scaffolding beforehand, the students could practice engineering without the presence of a teacher.

“...if this is just something they're doing in their pastime then it's just a recreational activity, but if it's teaching engineering, then it would be like watch this and then do something with it. Use some of the principles to either make your own bill, own dam or decide on what kind of things could've gone wrong or what things do they adjust."- - Houston responding to Scenario $3(106-111)$

“I would say that's definitely engineering 'cause it's, again they're identifying an issue, coming up with some possible solutions, testing their solutions. It sounds like a fun activity for them to do... It's not just a boring assignment..."-Victor responding to Scenario $11(411-415)$

\subsection{Response Differences between Math and Science Teachers}

As a whole, the majority of responses from both mathematics and science teachers shared many of the same elements. Both sets of teachers were quite conscious of the necessity for an engineering task to have a well-established sense of real- world applicability, and that through determining solutions to such problems, needs which exist at a higher level than the classroom would be addressed. In turn, both parties agreed that there needs to be some amount of communication to entities which exist outside of the classroom (e.g., administrators, community figures, etc.). They believed that it was not sufficient to simply conduct one trial of an experiment, but that it is essential to revisit the design process and allow for the manipulation of variables to note any observable variations in outcomes. It is in this way that the generating of multiple solutions may take place, and then from there-given certain parameters or constraints (i.e., classroom budget, or an intended 'optimization' goal), the most appropriate solution could be determined.

There were a couple of discourse differences that arose which were quite intriguing. Firstly, as mentioned above, both parties acknowledged that having a real-world context in a task was essential for the task to be considered practicing engineering. However, in their responses, science teachers generally made more frequent mentioning of specific examples for how the given scenario could be applied in a more 'real-world' way, whereas mathematics teachers more frequently ended their explanation after saying that a real-world applicability was necessary. This may be illustrated below through responses given by Briana (mathematics) and Daisy (science), respectively, when addressing the first scenario of: "Two students working on an assigned slope $y$-intercept problems for homework from their textbook."

“I feel like it's just like basic, traditional work and it doesn't have any application to it." (95-96)

"So I guess the way that I would push this more towards engineering is to... have them making a ramp and then try to figure out what the slope is." (219-220; 224-225)

Additionally, both sets of teachers agreed that a multistep challenge that involved the creation of a product/design/model, as well as a revision process, was necessary for the task to be considered engineering. Yet, science teachers were more inclined to talk about the specific manipulation of variables so as to observe variations in outcomes, whereas mathematics teachers, again, generally ended 
the discussion after simply stating the necessity of the components. This may be illustrated through responses from Abby (mathematics) and Mason (science) below, respectively. Where here, Abby is addressing scenario 8, and Mason is addressing scenario 6.

“They're not creating something new or using their own ideas ... " (537-538)

"...taking in consideration all of the variables that are in the parking lot scenario and then deciding what the best plan of action is." (523-525)

A final point worth mentioning was that both mathematics and science teachers were quite vocal that neither a task involving solely mathematics or science content was enough to be considered engineering. Rather, a union of the two must be present. This was encouraging to see, as too often these fields tend to keep to themselves rather than actively interact. It is hoped that through the inclusion of more engineering-based lessons in curricula, current communication barriers between these two disciplines may perhaps be dismantled.

\section{Discussion}

To review, the most frequently mentioned components of engineering conceived by the participants were: an Application/Real-World Context (16/16), Background Research (15/16), Experimentation (15/16), a Revision Process (15/16), Creating a Design/Product/Model (15/16), a Challenge/Multistep Problem (12/16), Brainstorming (10/16), and Communication (9/16). Both sets of teachers were conscious of the necessity for an applicable context to the task at hand, as well as ensuring that the scope of the solution to the challenge presented was larger than that of the classroom. Tasks should be presented such that students may explore multiple possible solutions, and after conducting experiments, a revision process should be had to improve the design process or the outcome obtained. It is also essential that students be made wary about concepts such as external parameters or constraints, namely: time, money, and available classroom resources.

A couple of discourse differences arose that were worth noting. Both sets of teachers acknowledged the need for real-world applicability, however the science teachers more frequently gave specific examples of how the given scenario could be applied, whereas mathematics teachers generally only mentioned that an application was needed. Similarly, both parties saw the importance of a multistep problem, exploring multiple solutions, and refining the process or design. Yet, science teachers more frequently mentioned the manipulation and tweaking of variables to look for observable changes in outcomes, whereas mathematics teachers, again, simply mentioned that these components were essential. Interestingly enough, both mathematics and science teachers were vocal that their specific content matter alone was not enough to define a task as being engineering. Instead, both must exist in harmony.

\section{Conclusions}

In recent years we have seen a resurgence of American schools investing in improving the quality of their mathematics and science education to equip students with 21st century inquiry skills in order to better tackle challenges that they will encounter post-graduation. As a result, $\mathrm{K}-12$ teachers are now being asked to carry out new educational standards and classroom practices, which have not been significantly explored and detailed in the literature. It is essential that we invest time in preparing our teachers for the challenges that they may face while implementing these new standards and practices if we truly wish to improve the quality of these classrooms. This study takes a first step in understanding the initial conceptions of engineering and teaching engineering held by secondary mathematics and science teachers. Results indicated that the participating teachers entered the PD program with some understanding of engineering processes, but very minimal specific content knowledge and information pertaining to engineering careers. It is hoped that through the utilization of tools like the CTE interview task, we may better design and tailor professional development programs to assist in expanding teachers' understanding of content knowledge, engineering processes, and engineering careers. 
Acknowledgments: The research reported in this paper was supported by a Mathematics and Science Partnership grant from the National Science Foundation [grant number 1102990]. Funding has also been received to cover the costs to publish in open access.

Author Contributions: Helen Meyer was responsible for helping to organize the overall PD program, and for collecting the CTE interview data. William Thatcher cleaned and coded the data, conducted the analyses, and wrote the paper.

Conflicts of Interest: The authors declare no conflict of interest.

\section{References}

1. Barnard, H. The Common School Curriculum, 1839 and 1841. In The American Curriculum: A Documentary History, 1st ed.; Greenwood Press: Westport, CT, USA, 1993.

2. National Governors Association Center for Best Practices and the Council of Chief State School Officers. Common Core State Standards for Mathematics. 2010. Available online: http:/ / www.corestandards.org/ (accessed on 5 July 2017).

3. NGSS Lead States. Next Generation Science Standards: For States, by States; National Academies Press: Washington, DC, USA, 2013.

4. Crismond, D. Learning and using Science Ideas when Doing Investigate-and-redesign Tasks: A Study of Naive, Novice, and Expert Designers Doing Constrained and Scaffolded Design Work. J. Res. Sci. Teach. 2001, 38, 791-820. [CrossRef]

5. Kolodner, J.L. Facilitating the Learning of Design Practices: Lessons Learned from Inquiry into Science Education. J. Ind. Teach. Educ. 2002, 39, 1-31.

6. Fan, S.-C.; Yu, K.-C. How an Integrative STEM Curriculum can Benefit Students in Engineering Design Practices. Int. J. Technol. Des. Educ. 2017, 27, 107-129. [CrossRef]

7. Hewson, P.W.; Hewson, M.G. Analysis and use of a Task for Identifying Conceptions of Teaching Science. J. Educ. Teach. 1989, 15, 191-209. [CrossRef]

8. American Association for the Advancement of Science (AAAS). Project 2061: Science for All Americans; Oxford University Press: New York, NY, USA, 1990.

9. Bybee, R.W. Scientfic and Engineering Practices in K-12 Classrooms: Understanding a Framework for K-12 Science Education. Sci. Teach. 2011, 78, 34.

10. Yasar, S.; Baker, D.; Robinson-Kurpius, S.; Krause, S.; Roberts, C. Development of a survey to assess teachers' perceptions of engineering and familiarity with teaching design, engineering and technology. J. Eng. Educ. 2006, 95, 205-216. [CrossRef]

11. Mehalik, M.; Doppelt, Y.; Schuun, C. Middle-School science through design-based learning versus scripted inquiry; Better overall science concept learning and equity gap reduction. J. Eng. Educ. 2008, 97, 71-85. [CrossRef]

12. Dym, C.L.; Agogino, A.M.; Eris, O.; Frey, D.D.; Leifer, L.J. Engineering Design Thinking, Teaching, and Learning. IEEE Eng. Manag. Rev. 2006, 34, 65. [CrossRef]

13. Katehi, L.; Pearson, G.; Feder, M. Engineering in K-12 Education: Understanding the Status and Improving the Prospects; National Academies Press: Washington, DC, USA, 2009.

14. Apple, Inc. Challenge Based Learning. 2001. Available online: http://www.challengebasedlearning.org/ public/admin/docs/CBL_Paper_October_2011.pdf (accessed on 5 July 2017).

15. Carr, R.L.; Strobel, J. Integrating Engineering Design Challenges into Secondary STEM Education; National Center for Engineering and Technology Education: Logan, UT, USA, 2011.

16. Klein, S.S.; Sherwood, R.D. Biomedical Engineering and Cognitive Science as the Basis for Secondary Science Curriculum Development: A Three Year Study. Sch. Sci. Math. 2005, 105, 384-401. [CrossRef]

17. Klein, S.S.; Geist, M.J. The Effect of a Bioengineering Unit across High School Contexts: An Initial Investigation in Urban, Suburban, and Rural Domains. New Dir. Teach. Learn. 2006, 2006, 93-106. [CrossRef]

18. Cordray, D.S.; Harris, T.R.; Klein, S. A Research Synthesis of the Effectiveness, Replicability, and Generality of the VaNTH Challenge-Based Instructional Modules in Bioengineering. J. Eng. Educ. 2009, 98, 335-348. [CrossRef]

19. Calderhead, J. Teachers: Beliefs and Knowledge. In Handbook of Educational Psychology; Berliner, D.C., Calfee, R.C., Eds.; MacMillan: New York, NY, USA, 1996; pp. 709-725. 
20. Brickhouse, N.W. Teachers' Beliefs about the Nature of Science and their Relationship to Classroom Practice. J. Teach. Educ. 1990, 41, 53-62. [CrossRef]

21. Case, J.M. Emergent Interactions: Rethinking the Relationship between Teaching and Learning. Teach. High. Educ. 2015, 20, 625-635. [CrossRef]

22. Guskey, T.R. Professional Development and Teacher Change. Teach. Teach. 2002, 8, 381-391. [CrossRef]

23. Loughran, J. Pedagogy: Making Sense of the Complex Relationship between Teaching and Learning. Curric. Inq. 2013, 43, 118-141. [CrossRef]

24. Osborne, R.; Gilbert, J. An Approach to Student Understanding of Basic Concepts in Science; University of Surrey: Guildford, UK, 1979.

25. Osborne, R.J.; Gilbert, J.K. A Technique for Exploring Students' Views of the World. Phys. Educ. 1980, 15, 376-379. [CrossRef]

(C) 2017 by the authors. Licensee MDPI, Basel, Switzerland. This article is an open access article distributed under the terms and conditions of the Creative Commons Attribution (CC BY) license (http://creativecommons.org/licenses/by/4.0/). 